\title{
Integrating the Auction and Role-play Game into Eng- lish Speaking Class
}

\author{
Xinyue Deng ${ }^{1, \dagger}$, Xiusong Qin ${ }^{2, *}, \dagger$, Xiaoqing Yuan ${ }^{3, \dagger}$, Xiaoxin $\mathrm{Zhou}^{4, \dagger}$ \\ ${ }^{1}$ School of Prospect College, Chongqing College of Mobile Communication, 400000, Chongqing, China \\ ${ }^{2}$ School of Ontario Institute for Studies in Education, University of Toronto, M5S2E8, Toronto, Ontario, Canada \\ ${ }^{3}$ School of Philosophy and Social Development, South China Normal University, 510000, Guangzhou, Guangdong, \\ China \\ ${ }^{4}$ School of Physical Arts, Guangzhou Sport University, 510000, Guangzhou, Guangdong, China \\ ${ }^{*}$ Corresponding author. Email: xiusong.qin@mail.utoronto.ca
}

These authors contributed equally.

\begin{abstract}
.
This study explores the effect of games (e.g., the auction and role-play game) in teaching spoken English among Chinese middle school students. Five participants were divided into two groups and given online courses with and without games for comparisons. This research utilized a qualitative method to collect data from their pre-class tests, students' performance in class, after-class tests, followed by brief reflections towards the content, teaching methods, and participants' own gains. Compared with the control group's results (the group without games) in which one participant was taught without any use of games, the effect is evaluated from six perspectives: confidence, fluency, vocabulary, grammar, logic, and pronunciation. The data provides valuable information on games' role in teaching and learning spoken English. The findings suggest that games can increase students' confidence and willingness to express themselves, helping them achieve more obvious improvement in their speaking fluency and make more prominent progress in English vocabulary. Even though the result of oral performance in grammar varies from person to person, and the class fails to make a difference, which is detectable enough to participants' logic and pronunciation, there are still reasons to believe that more progress shall be made with better-designed games and more in-time feedback in the class.
\end{abstract}

Keywords: English speaking, Game class, Vocabulary, Confidence, Fluency, Pronunciation

\section{INTRODUCTION}

\subsection{Research Background}

According to IELTS test statistics of the test taker performance in 2019, test takers from China had the lowest average speaking band score among the forty countries. Although it remains a question that "to what extend can IELTS speaking test reflect ESL learners' oral English proficiency or ability to achieve successful communication in English," this statistic reveals the fact that speaking, compared with other aspects in learning English, is the most neglected one in the education system in China and among Chinese ESL learners. Therefore, in this research, we will focus on teaching oral English, especially from the perspectives of confidence, fluency, grammar, vocabulary, logic, and pronunciation among
Chinese middle school students with games, such as the auction and role-play game.

\subsection{Literature Review}

As Steen and Owens noted, pretence, one of the most significant features of games, was a significant and ubiquitous feature of mammals, especially human beings [1] Therefore, integrating games, whose nature is pretense, into teaching can cater to such nature and improve the effectiveness of our class.

Gibson's theory concerning affordances is also valuable for this research since it emphasized the complementarity of the animal and the environment, which is what games can help to achieve. In the case of play, affordances are a function of the needs of the individual. 
Bruner's theory concerning the active discovery of students also reflected the role of teachers, which was creating a suitable and comfortable environment for students to explore freely [2]. Bruner also mentioned the bigger challenge for our memory was the retrieval rather than the volume (p. 64). The game is an efficient method to make our knowledge memories more vivid and retrievable [2]. As Bruner argues, intrinsic motivate is more effective in controlling "long-range and competence-oriented" behaviors, which is exactly the characteristic of spoken English [2].

According to Nazarova and Galiullina, teaching and learning English with game activities can help improve students' communication skills, overcome the fear of spontaneous communication for the target language, create more opportunities for cooperation and partnerships while at the same time bringing about favorable situations and conditions for students to speak [3].

In general, there have been a large number of endeavors to integrate different games into ESL teaching practice to make the class more attractive and engaging to students. However, few focused on the effect of games like the auction in teaching spoken English, which can improve students' speaking performance from the perspectives of grammar and vocabulary.

\subsection{Research Objective}

To design a class and see how games like the auction and the role-playing game can help students improve their spoken English.

\section{RESEARCH DESIGN}

\subsection{The Criteria for Selected Participants}

The participants had to be Chinese middle school students who have a minimum of some knowledge in spoken English.

The participants had to be able to converse in Mandarin and English.

They should have at least a limited proficiency with their oral English.

\subsection{Participants}

After selections, 5 Chinese middle school students participated in this research

Table 1. Participants' demographic information

\begin{tabular}{llll}
\hline Name & Age & Grade & Gender \\
\hline P1 & 13 & 1 & $M$ \\
P2 & 14 & 2 & $M$ \\
P3 & 13 & 1 & $M$ \\
P4 & 13 & 1 & $M$ \\
P5 & 14 & 2 & $F$ \\
\hline
\end{tabular}

\subsection{Methods for Data Collection}

\subsubsection{The online class with games}

Four participants (except P5) attended the online English class, lasting about one hour, and taught with two games.

In the auction (game 1), each participant was given a certain amount of virtual money, which they can use to bid. The lots in this auction were vocabularies and sentence patterns concerning food, such as "bread" and "...at dinner". (There were distractors, which were irrelevant with the topic, such as "bridge" and "cherish"). Once getting his lot(s) with the highest price, the participants had to form a complete sentence or paragraph with it(them) and read it. The score was determined by the number of lots included in the sentence, the accuracy of the sentence structure, and the accuracy of pronunciation.

In the role-playing game (game 2), the participants worked in groups to play two characters (waiter\& customer) in the context of ordering food in the diner. There were a total of 4 phases in this game. Firstly, the instructor presented some vocabularies and expressions which are commonly used. Then, the participants gave their performance. After that, the instructor would offer some suggestions for improvement. Finally, the participants performed again.

\subsubsection{The online class without games}

One participant(P5) attended the online English class without the specially-designed games, and in this class, the same teaching content was presented and taught differently. In the beginning, the instructor directly presented many relevant vocabularies to Huang and asked her to point out those that she was not familiar with. Then, Huang was told their meaning in Chinese and read after the instructor one by one. After that, the relevant sentence structures and phrases were taught to Huang in the same way, and then she was required to create complete sentences with them and alter the sentence pattern while not changing the meaning. Finally, the instructor tried to reinforce the knowledge by asking questions and playing a waitress to take Huang's order.

\subsubsection{Speaking tests before and after the class}

Two speaking tests concerning the topics covered in the class were included in this research, and each lasted approximately ten minutes.

\subsubsection{Video recordings}

Both the class and the speaking tests were recorded to provide an accurate reference of what was said 


\subsubsection{After-class Reflections}

Participants were asked to give a brief reflection after the whole class, including the content, teaching methods, and gains.

\subsection{Methods for Data Analysis}

\subsubsection{Comparative Analysis}

The reason why selecting comparative analysis in this research is that comparing participants' performance between the speaking tests before and after the class can reflect the effect of the games in teaching spoken English.

\subsubsection{Triangulation of Data}

We triangulated the before-class speaking test results, the after-class speaking test, and the after-class reflections of participants.

It ensured the validity and trustworthiness of this research since the consistencies and discrepancies between the different sets of data can be found and included as part of the final results

\section{RESULTS}

\subsection{Comparison of Test before and after Game Class}

\subsubsection{Confidence}

In the pre-class test, the students were not active. Regarding the role-playing game, the teacher needed to call which student to play what role, especially P1 and P2. In addition, $\mathrm{P} 3$ and $\mathrm{P} 4$ do not have enough sentence patterns accumulation to support them to complete the whole long dialogue because of their limited English level. P5 was not active or skeptical herself.

In the after-class test, Wang took the initiative to organize and carry out the game. Song and Chen can speak longer dialogue than before.

Transcript 1:

P3: We don't have seafood.

P4: OK. How much are these?

P3: It's twenty Yuan.

P4: Here you are.

P5 believed herself and answered the familiar questions correctly. Therefore, students had an improvement in confidence to speak English after the class.

\subsubsection{Fluency}

After the teacher asked questions in the pre-class test,
P1, P2, and P5 thought for more than 10 seconds and answered intermittently many times. P3 and P4 had the desire to express themselves well, but they had more pauses. They cannot speak difficult sentences fluently and accurately or cannot express what they want to say.

In the after-class test, the two students' (P1 and P2) thinking time and the number of pauses decreased. Huang's situation was the same as theirs when she met old questions. P3 and P4 were much better in using simple sentences, indicating that students' oral fluency improved.

\subsubsection{Grammatical Accuracy}

In the pre-class test, Student Wang, Student Zhao, and Student Huang made grammatical mistakes.

Transcript 2:

Teacher: Why do you like apples?

P2: Because apples are delicious.

...

Teacher: What are you interested in the shop?

P5: I am interested in the green dress.

P1, P2, and P5 did not make so many grammatical mistakes in the after-class test. Therefore, they had improvements in this part.

As for P3 and P4, simple short sentences were okay for them, but in the usage of more complex sentences, there was a logical confusion and incomplete sentence structure. They did not pay attention to the changes of singular and plural numbers nouns in sentences. There were also obvious cases of giving up trying to make the whole sentence because of being afraid of sentence grammar problems. There were few improvements in the accuracy of grammar use after class.

\section{Transcript 3:}

P4: I want to have a cold drink.

P3: We have many specials, they are beef noodles and fruit juice. It's only ten Yuan. How about the specials?

\subsubsection{Richness of Vocabulary and Sentence Pat- terns}

Students often answered with only a single word, a phrase, or simple sentence patterns in the pre-class test. Students used the words and sentence patterns they had learned in the game class in the after-class test.

Transcript 4:

Teacher: Do you think you eat healthy food?

P1: I think I have healthy eating habits. In the morning, I will eat eggs for my breakfast. 


\subsubsection{Pronunciation}

Both $\mathrm{P} 1$ and $\mathrm{P} 2$ had pronunciation mistakes in the pre-class test and after-class test. For example, students mispronounce the words yogurt, have, badminton and dessert.

Therefore, students showed no significant improvement in pronunciation. And there are still some pronunciation problems in the expression of sentences. It may be related to students' previous English learning habits and focus. Junior middle school students often have less energy in learning English vocabulary and pronunciation.

\subsubsection{Ideas and Logic}

Participants' logic of answers has been improved compared with before. In the after-class test, students talked more about questions compared with the pre-class test. P1 and P2 have an improvement on ideas and logic, especially on the topic of food. But between P3 and P4, due to the limitation of their English level, another student will not reply and understand well when one of them is speaking in their ways.

Transcript 5:

P4: ...I else like sea... seafood. Please, can you get me some advice.

P3: It's ...20 Yuan.

Teacher: Which kind of food do you like most?

P1: I like apples because an apple a day keeps the doctor away.

\subsection{The Result of the Control Group(P5)}

In terms of the control group, it consisted of three parts, the pre-class test, the class, and the after-class test. P5 was the only participant in this section.

\subsubsection{The Pre-class Test}

There were eight questions and a dialog about food and shopping in the test. But P5 did not do well in the test, and she could answer just half of the questions logically. Her answers exposed several problems P5 came across while speaking English. Firstly, she was lack of vocabulary and used the same word several times. Secondly, her preference for answering questions with one word or short phrase rather than complete sentences. Thirdly, the meaning of some parts of the speech and sentence structure was not clear enough, resulting in grammatically incorrect sentences when she tried to give complete sentences.

\section{Transcript 6:}

Teacher: What kind of food do you like most?
P5: Snacks.

Teacher: Why?

P5: ...(Without saying a word)

\subsubsection{The Class}

The instructor teaches P5 some vocabulary, phrases, and sentence patterns related to food and shopping. Then forming sentences with the given materials. In addition, P5 needed to give three answers when the instructor asked her a question. At the beginning of the class, P5 had more new words, and her reaction was slow. Sentence structure always went wrong when trying to say a complete sentence. However, she actively cooperated with the instructor during the class and treated it seriously. At the end of it, P5 made some progress and could give grammatically correct and complete sentences.

Transcript 7:

Teacher: What kind of food do you like most?

P5: I like snacks most. I like meat most. I like fruits most.

Teacher: Why do you like meat most?

P5: Because it is delicious.

$\cdots$

P5: How much is the sweater?

Teacher: This is a wrong sentence because it lacks predicate (is). The correct one is " how much is your sweater."

\subsubsection{After-class Test}

It was similar to the Pre-class test with eight questions, including four new and four old ones and a situational conversation (food and shopping). P5 still answered half of the questions correctly while couldn't finish the situational conversation fluently. She could slowly talk about some relevant content. P5 has improved the answers concerning old topics and used grammatically correct and complete sentences. However, she still couldn't respond to the new topic well.

In general, there is no significant difference between the results of the two tests since both of them were halffinished correctly. However, P5 still had some gains from the class, especially from the perspective of sentence structure, although they were not so obvious.

The instructor used the following six standards to measure P5's improvement (confidence, oral fluency, grammatical accuracy, vocabulary and richness of sentence patterns, pronunciation, and logical thinking). P5's improvement in the after-class test lies in all six parts. Perhaps it can be attributed to the similar topics that she 
had access to in the pre-class test. When facing new questions, P5 did not show great improvement or even did a little worse, which indicates the limited effect of this "traditional class".

\section{Transcript 8:}

Teacher: What kind of food do you like most? ( It is an old question.)

P5: I like fruits most, like oranges, apples, grapes and so on. Because they are delicious.

Teacher: Tell me about your recent experience of shopping. (It is a new question.)

P5: I bought a schoolbag last weekend. (The grammar was wrong in this sentence, she should use the word "bought" instead of "buy".)

Teacher: Where did you buy it?

P5: In the shopping center.

\section{DISCUSSION}

\subsection{Traditional Class}

Zhang argues that vocabulary learning must be combined with listening and practicing; language learning cannot be conducted successfully without listening and speaking practice[4]. Like the traditional teaching method, in our class, the teachers guided the students to read and speak the words again and again to improve their deeper memory of the words. After the students mastering, they still need a large number of practices to consolidate the related knowledge. Song points out that oral English is an unbridgeable gap in learning for students. Under this kind of psychological fear, students' initiatives are seriously destroyed. In other words, students' mental fear means that they are not confident enough in terms of oral English [5]. Zhou notes that some students have difficulty in speaking English since they are afraid of being laughed at by their classmates and criticized by their teachers [6]. Therefore, they are not good at expressing themselves in English. According to our result, Participant 5 is one of the students with this kind of situation, who is typically scared to speak out loudly. Zhou also mentions that the teaching method is limited and singular because the teachers only focus on repeating knowledge instead of adding something interesting into the class [6]. Therefore, Participant 5 said that the class was lack of attraction, and the atmosphere made her feel embarrassed.

\subsection{Game Class}

\subsubsection{Confidence}

Games increase students' confidence and willingness of expressing themselves while promoting class interaction at the same time.
Shao surveyed two classes of grade five students in a primary school [7]. In the experimental class, the activity teaching method was adopted to teach oral English to students [7]. In the control class, a traditional teaching method was adopted to teach oral English to students. Other teaching factors remained the same. Shao learns from the survey that the activity teaching method can create an environment for students to practice English, stimulate their interest in Learning English, enhance their enthusiasm in learning English, and improve their confidence in speaking English [7]. In this paper, the comparison between a traditional class and a game class in this respect was also noticeable. Students talked more in the game class when compared with the traditional class. With more practice, students became more confident when speaking English, and they were more active in taking chances to speak a foreign language, instead of scaring and bashfulness. Other studies also prove this positive change brought by games to language class. Han suggests that games can enliven the classroom atmosphere, encouraging students to read new words loudly, quickly, and clearly, to compete with each other in speed and accuracy [8]. Students' enthusiasm for participation is mobilized by games, making them more active in expressing loudly and bravely, instead of doubting their own capability.

\subsubsection{Fluency}

Those attending the game class show more obvious improvement in their fluency of speaking.

Han experimented with the influence of guessing games on spoken English, which proves that the students' oral fluency has improved significantly, mainly because of the large number of opportunities to practice some sentences with the same structure in the guessing class. In contrast, each sentence has a different new meaning [9]. Meaningful repetition improves fluency by facilitating the programming of knowledge and automating language extraction. In addition, in the game, the teacher is not as strict as usual to control the classroom completely. On the contrary, the classroom atmosphere is relatively relaxing, and students need not be afraid of giving wrong sentences or being criticized by the teacher. In such a class, the teacher tends to concentrate more on students' way of thinking and endeavors to help them guess the word. Few students think about the grammar of their sentences, and few teachers corrected students' grammatical mistakes. Therefore, with many students focus on what to say and speak actively, this kind of meaning-based oral practice can naturally improve students' oral fluency. It is obvious that students will become familiar with the knowledge if they participate in games, including a large amount of practice. In this research, the change in fluency appears the same. All of the participants improved after the class, while we can see this result is more obvious for those who participated in the game class. 


\subsubsection{Grammar}

The game class helps some participants increase their English grammar more obviously than the traditional class, while the others make little progress.

Metin and Sarıçoban point out that games and other communicative tasks are suitable as practice for students to learn the grammar since they would need sufficient grammar and lexical points to handle them [10]. More importantly, they also mention that by establishing an ideal situation for language use, well-designed games can help their participants to "practice and internalize vocabulary, grammar and structures extensively [10]." Moreover, Ishtawi argues that game strategy positively impacts students' understanding and proficiency of grammar, and they are likely to have an obvious improvement in their achievement [11]. However, our research presents a more complex result. The number of grammatical mistakes made by Wang and Zhao decreased while there is little improvement in Song and Chen's performance. Gruss argues that since each group of learners is different, the effectiveness of games teaching and learners' preference of games vary to a large extent, which helps explain and justify our results, even though Gruss focuses on vocabulary acquisition in her research [12]. In general, due to some potential flaws in the design of our games and individual difference of the participants, the effect on the grammar of some participants is more obvious than that of the others.

\subsubsection{Vocabulary}

All four participants who attended the game class make more prominent progress in English vocabulary than the student in traditional classes.

The results present that all four participants showed detectable progress in the after-test from the vocabulary perspective, which resonates with Shabaneh and Farrah's findings. Like Gruss, who argues that games as a teaching approach for vocabulary have infinite and obvious potentials, Shabaneh and Farrah also believe that games, by connecting new information with surroundings, can help students retain unfamiliar words [12,13]. Participant 1 in the after-class reflection specially mentioned that the existence of distractors in the first game helped him memorize the meaning of at least one word (stick) clearly. However, Diana pinpoints some drawbacks of games in conveying knowledge about vocabulary, which also appeared in our class [14]. For instance, while attracting students' interest and attention, games sometimes make them too active and noisy, and the condition could even become uncontrollable. More importantly, as the time devoted to the process of games increases, less attention and time will be given to the content and explanation of it, which was exactly what happened to our class. That was why we just finished a small part of the prepared material.

\subsubsection{Logic}

Participants of the game class gradually improve their logic in constructing their answers for the questions which are not presented in the result of the after-class test.

Jiang proposes that students should be given a relaxing and pleasant environment by the English teacher so that the class would better coalesce the process of teaching and learning and reflect the value of learning in oral dialogue [15]. In such a class, the student can improve their oral application skills and logical thinking skills. In our research, the four students who participated in the game class showed some slight improvement in their logic of speaking English, although the result of the afterclass test did not change a lot., However, we can still conclude that their mind of thinking is widened and broadened because the immersive dialogue made them get used to the second language's expression.

\subsubsection{Pronunciation}

Participants of the game class should have made larger progress in pronunciation if more in-time feedback and correction could be provided.

Nevertheless, Zhang proposes that it is very important to create a real scene of spoken English to make students handle accurate oral pronunciation [16]. In addition, good strategies are also very important, which determine if all students are integrated well into the class and learn something that truly increases their knowledge of oral English. In contrast, our game class of spoken English maybe not be that well-rounded. It is important to pay attention to the in-time feedback and correction to students' pronunciation, even if it is a rather cumbersome process.

\section{CONCLUSION}

Games can be a supportive tool to improve different aspects of students' speaking performance in English compared with the class without games. Such a teaching approach also has its unique benefits. From the perspective of confidence, the game class has proven itself more effective than the without games by improving students' willingness to express themselves. Moreover, with the assistance of games, students have a different way to familiarize themselves with new words. The new words can leave deeper impressions to the learners, making more prominent progress in vocabulary. Furthermore, participants' fluency in speaking also increases more obviously with the help of games. Although the result in grammar varies from person to person, which means half of the participants fail to perform better in this aspect, and nor does it make a more detectable difference to participants' logic and pronunciation of speaking, this teaching approach is still promising with more refined games and intime feedback in class. 
The limitation is that there are only five participants who have poor spoken English. It is a qualitative study that does not contain much data, which is not insufficiently representative. Due to time, resources, and pandemic constraints, the design and implementation of games were not detailed enough. In this research, the class time of game class and tradition class were both not long enough to adequately reflect the effect of games. In addition, due to the small number of participants and the limitation of online classes, there was a lack of sufficient classroom atmosphere and a sense of classroom involvement.

Moreover, in future research, the game class could be well continued to experiment under the situation of enough time and people in schools or professional education institutions. Then look at the results of the research whether it becomes better. What's more, the form of games can be more diverse, for instance, dancing, drama, storytelling, etc. In addition, it is no more limited by traditional classroom games. Moreover, it is crucial to compare the effect between different games instead of just compare the situation with games or without games.

\section{REFERENCES}

[1] Steen, F., \& Owens, S. (2001). Evolution's Pedagogy: An Adaptationist Model of Pretense and Entertainment. Journal of Cognition and Culture, 1(4), 289-321.

https://doi.org/10.1163/156853701753678305

[2] Bruner, J. S. (1961). The act of discovery. HarvardEducational Review, 31, 21-32.

[3] Nazarova, M. \& Galiullina, E.(2016). Gamebased learning in teaching English. Journal of Organizational Culture, Communications and Conflict. 20. 812.

[4] Zhang. F.F. (2019). English phonics is applied in junior one. Shanxi education teaching version)(Z2),75. doi:10.13617/j.cnki.sxnedu.2019.z2.057.

[5] Song. M.L. (2021). explore and analysis junior high school oral English. Charm of China(3), 283-284.

[6] Zhou.J.(2021) . the problems and improvement strategies study in junior high school oral

[7] Shao. F.F. (2017). A Study on the Application of activity Teaching method in Oral English teaching in primary Schools school. Shenyang Normal University.

[8] Han. B.L. (2015). Improving spoken English for primary school students through guessing games. Inner Mongolia Normal University.

[9] Han.T. Y. (2008). Self-confidence and oral English training. Foreign language teaching and research.
[10] Saricoban, A., \& Metin, E. (2000). Songs, verse and games for teaching grammar. The Internet TESL Journal, 6(10), 1-7.

[11] Ishtawi, H. R. M. (2011). The Effects of Game Strategy on the Learning of English Grammar for the Twelfth Grade Students. the islamic university. http://hdl.handle.net/20.500.12358/17599

[12] Gruss, J. (2016). Games as a tool for teaching English vocabulary to young learners. World · Scientific News, 53(2), 67-109.

[13] Shabaneh, Y., \& Farrah, M. (2019). The effect of games on vocabulary retention. Indonesian Journal of Learning and Instruction, 2(1), 7990.doi:10.25134/ijli.v2i01.1687.

[14] Diana, N. P. R. (2010). The advantages and disadvantages of using games in teaching vocabulary to the third graders of top school elementary school. Final Project Report. Sebelas Maret University.

[15] Jiang. B. (2013). The influence of communicative language testing on oral English teaching. Harbin Normal University.

[16] Zhang. W. W. (2017). Some thoughts on Oral English pronunciation teaching. Liangzou Primary School in Zouping County, Shandong Province. 